\title{
Applying van Hiele's Levels to Basic Research on the Difficulty Factors behind Understanding Functions
}

\author{
Yoshiki Nisawa ${ }^{1 *}$ \\ ${ }^{1}$ Department of Education, Faculty of Education, Bukkyo University, Kyoto, JAPAN

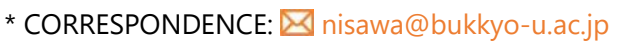

\begin{abstract}
Functions is considered an important mathematical literacy concept within the Organization for Economic Cooperation and Development's (OECD's) Programme for International Student Assessment (PISA), and it has been shown that Japanese junior high school students are experiencing problems understanding functions. This paper examines the difficulty factors behind the understanding of functions by referring to van Hiele's theory of learning levels. This paper focuses on the prototypical stages for understanding functions from the perspective of the mathematical concept process model of gradual understanding: ' $[1]$ Extract a variate from a phenomenon and [II] Relate the 2 extracted variates'. The subjects of the study were junior high school students, who completed a questionnaire. The results of the analysis of the questionnaire responses found that for a certain number of students, concept formation for stages [I] and [II] was lacking, and that the situation was not necessarily improving as the class progressed, thus, suggesting that this may be a difficulty factor that affects the understanding of functions.
\end{abstract}

Keywords: function understanding, difficulty factor, van Hiele's theory, extract variables, relate the two extracted variates

\section{INTRODUCTION}

'Change and relationships' is a mathematical content area within the mathematical literacy section of the Organization for Economic Cooperation and Development's (OECD's) Programme for International Student Assessment (PISA), which indicates the importance of learning about functions and concepts (OECD, 2017). There is more research than ever before on mathematics education in Japan with regard to teaching functions (Japan Society of Mathematical Education, 2010, pp. 142-157). However, a comparison of the average percentage of correct answers across the fields 'Numbers and Algebraic Expressions', 'Geometrical Figures', 'Functions' and 'Making Use of Data', which are found in the annual National Assessment of Academic Ability (National Institute for Educational Policy Research, 2014, 2015, 2016, 2017), shows a decline in the percentage of correct answers in the field of 'functions' compared with the other fields, suggesting problems related to understanding. The percentage of correct answers in the 'functions' field of the National Assessment of Academic Ability have tended to be lower in comparison to the other fields, and in addition, in 2014 and 2017 , it was indicated that there was a problem in students 'understanding the meaning of functions'. Regarding the meaning of functional relationships, in the first year of junior high school, the aim is to deepen the understanding, by paying attention to the indications of change and relationships, that a functional relationship means that for two related quantities, if one of the values is fixed, the other value is fixed in relation to it. Here, the relationship between the two quantities is understood using expressions such as 'and ... is a functional relationship', 'is the function of (Ministry of Education, Culture, Sports, Science and

Article History: Received 11 April $2018 \bullet$ Revised 13 May $2018 \bullet$ Accepted 26 May 2018

(C) 2018 The Author(s). Open Access terms of the Creative Commons Attribution 4.0 International License (http://creativecommons.org/licenses/by/4.0/) apply. The license permits unrestricted use, distribution, and reproduction in any medium, on the condition that users give exact credit to the original author(s) and the source, provide a link to the Creative Commons license, and indicate if they made any changes. 
Technology, 2008, p. 73). Thus, the 'meaning of functions' is based on the stages '[I] Extract a variate from a phenomenon, [II] Relate the 2 extracted variates', and these understandings should deepen as the grade progresses.

Here, van Hiele's theory of learning levels (1986) can be used as a research tool that can illustrate the state of gradual mathematical thinking clearly. According to this theory, as a process model of understanding, five levels of thinking and five stages of learning can raise the level of thinking. The five levels of thinking are Level 0 (Visualisation), Level 1 (Analysis), Level 2 (Informal Deduction), Level 3 (Deduction) and Level 4 (Rigour), and, characteristically, raising the level is understood as 'objectifying the method'. For example, at Level 0, the objects surrounding us are the targets of our thinking, and as the method of thinking, we focus on the shape by observing and distinguishing these objects. At Level 1, we take the 'shape' that was the method of thinking in Level 0 as the target of thinking, and as the method of thinking, we focus on its properties and distinguish it. In this way, we transition to the higher levels. Moreover, since students' thinking is voluntary, to get students themselves to think voluntarily, they require motives, intentions and an understanding of the object of their observations. A study by Fuys, Geddes and Tischler (1988) validated the van Hiele's theory among adolescents, and Usiskin (1982) also conducted validation studies.

van Hiele's levels, which are usually applied to geometry teaching, can also be applied to analysing students' understanding of other mathematical topics (Colignatus, 2014), such as functions (Isoda, 1987; Land, 1990) and trigonometry (Walsh, 2015).

Therefore this paper aims to examine the difficulty factors behind understanding functions by referring to research on understanding mathematical concepts through applying van Hiele's theory of learning levels.

\section{METHOD}

To address the problem, we focused on the stages for teaching functions, '[I] Extract a variate from a phenomenon, [II] Relate the 2 extracted variates', and carried out a study of stages [I] and [II] by distributing a questionnaire to junior high school students. Then we analysed the data that was gathered, to examine the difficulty factors behind understanding functions.

The study focused not only on first-year junior high school students (12-13 years old) but also on secondand third-year students (13-15 years old); therefore, it considered the degree to which the students retained stages [I] and [II] as their classes progressed. The details of the study are as follows:

Study subjects: Public junior high school in Osaka prefecture

Year 1 (12-13 years old, 5 classes, 160 students)

Year 2 (13-14 years old, 5 classes, 152 students)

Year 3 (14-15 years old, 5 classes, 147 students)

Date: End of October 2015

Materials: Questionnaire (approximately 20 minutes)

Note 1: Junior high school textbooks devote a page to reviewing 'varying amounts' as taught in elementary school, before moving on to functions. However, the extent of a student's ability to extract variables from events, and the degree to which this ability will advance, is not always clear. We believe it is necessary to assess the degree to which students are equipped with these abilities.

Note 2: In the first year, students learn about the definition of functions, proportionality, proportionality equations and coordinate planes in the unit 'Change and Relationships'. They have not yet learned about proportionality graphs. In the second year, they learn about 'linear functions'. In the third year, they learn about the 'function $\mathrm{y}=\mathrm{a} \mathrm{x}^{2}$ ',

Note 3: We received informed consent from the junior high school subjects for their participation in the questionnaire.

Numerous questions were formulated for the study; however, this paper discusses only questions (1) and (3) (shown in Figure 1) and examines subquestions (i) and (ii) for questions (1) and (3) and considers teaching with a focus mainly on the amount of change with regard to Japanese primary and junior high schools. 

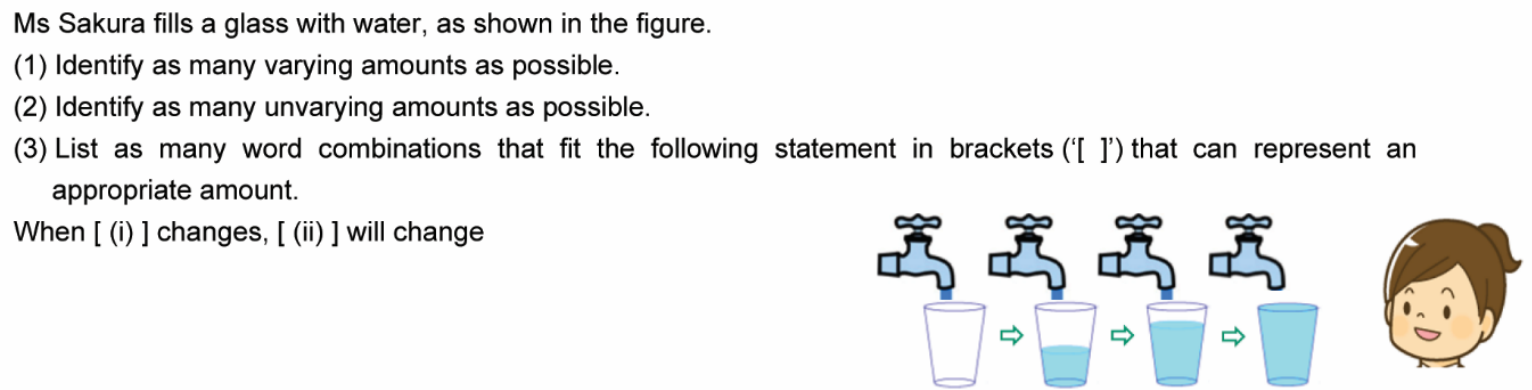

Figure 1. The survey questions

Table 1. Number of Students and Percentage of Appropriate Answers to Question (1) (Percentage rounded to one decimal place)

\begin{tabular}{|c|c|c|c|c|c|c|c|c|}
\hline \multirow{2}{*}{$\begin{array}{l}\text { Number of } \\
\text { appropriate } \\
\text { answers } \\
\text { (pieces) }\end{array}$} & \multicolumn{2}{|c|}{$\begin{array}{c}\text { The } 1^{\text {st }} \text { grade } \\
\text { group A }\end{array}$} & \multicolumn{2}{|c|}{$\begin{array}{c}\text { The } 1^{\text {st }} \text { grade } \\
\text { group B, C, D, E }\end{array}$} & \multicolumn{2}{|c|}{ The $2^{\text {nd }}$ grade } & \multicolumn{2}{|c|}{ The $3^{\text {rd }}$ grade } \\
\hline & $\begin{array}{c}\text { Number of } \\
\text { students }\end{array}$ & $\begin{array}{c}\text { Percentage } \\
(\%)\end{array}$ & $\begin{array}{c}\text { Number of } \\
\text { students }\end{array}$ & $\begin{array}{c}\text { Percentage } \\
(\%)\end{array}$ & $\begin{array}{c}\text { Number of } \\
\text { students }\end{array}$ & $\begin{array}{c}\text { Percentage } \\
(\%)\end{array}$ & $\begin{array}{c}\begin{array}{c}\text { Number of } \\
\text { students }\end{array} \\
\end{array}$ & $\begin{array}{c}\text { Percentage } \\
(\%)\end{array}$ \\
\hline 5 or more & 0 & 0.0 & 3 & 2.3 & 2 & 1.3 & 3 & 2.0 \\
\hline 4 & 0 & 0.0 & 3 & 2.3 & 13 & 8.6 & 5 & 3.4 \\
\hline 3 & 1 & 3.3 & 34 & 26.2 & 10 & 6.6 & 20 & 13.6 \\
\hline 2 & 5 & 16.7 & 31 & 23.8 & 41 & 27.0 & 37 & 25.2 \\
\hline 1 & 6 & 20.0 & 31 & 23.8 & 40 & 26.3 & 49 & 33.3 \\
\hline 0 & 18 & 60.0 & 28 & 21.5 & 46 & 30.3 & 33 & 22.4 \\
\hline Total & 30 & 100.0 & 130 & 99.9 & 152 & 100.1 & 147 & 99.9 \\
\hline
\end{tabular}

Table 2. Number of Students and Percentage of Appropriate Answers to Subquestions (i) and (ii) for Question (3) (Percentage rounded to one decimal places)

\begin{tabular}{|c|c|c|c|c|c|c|c|c|}
\hline \multirow{2}{*}{$\begin{array}{l}\text { Number of } \\
\text { appropriate } \\
\text { answers } \\
\text { (pieces) }\end{array}$} & \multicolumn{2}{|c|}{$\begin{array}{c}\text { The } 1^{\text {st }} \text { grade } \\
\text { group A }\end{array}$} & \multicolumn{2}{|c|}{$\begin{array}{c}\text { The } 1^{\text {st }} \text { grade } \\
\text { group } \mathrm{B}, \mathrm{C}, \mathrm{D}, \mathrm{E}\end{array}$} & \multicolumn{2}{|c|}{ The $2^{\text {nd }}$ grade } & \multicolumn{2}{|c|}{ The $3^{\text {rd }}$ grade } \\
\hline & $\begin{array}{c}\text { Number of } \\
\text { students }\end{array}$ & $\begin{array}{c}\text { Percentage } \\
(\%)\end{array}$ & $\begin{array}{c}\text { Number of } \\
\text { students }\end{array}$ & $\begin{array}{c}\text { Percentage } \\
(\%)\end{array}$ & $\begin{array}{c}\text { Number of } \\
\text { students }\end{array}$ & $\begin{array}{c}\text { Percentage } \\
(\%)\end{array}$ & $\begin{array}{c}\begin{array}{c}\text { Number of } \\
\text { students }\end{array} \\
\end{array}$ & $\begin{array}{c}\text { Percentage } \\
(\%)\end{array}$ \\
\hline 5 or more & 1 & 3.3 & 3 & 2.3 & 0 & 0.0 & 1 & 0.7 \\
\hline 4 & 0 & 0.0 & 3 & 2.3 & 0 & 0.0 & 0 & 0.0 \\
\hline 3 & 1 & 3.3 & 5 & 3.8 & 4 & 2.6 & 5 & 3.4 \\
\hline 2 & 2 & 6.7 & 17 & 13.1 & 26 & 17.1 & 11 & 7.5 \\
\hline 1 & 4 & 13.3 & 46 & 35.4 & 44 & 28.9 & 35 & 23.8 \\
\hline 0 & 22 & 73.3 & 56 & 43.1 & 78 & 51.3 & 95 & 64.6 \\
\hline Total & 30 & 99.9 & 130 & 100.0 & 152 & 99.9 & 147 & 100.0 \\
\hline
\end{tabular}

We totalled the number of what was determined as appropriate variates among the students' answers (Tables 1 and 2). For experimental groups B, C, D and E from the first year (130 students), the teacher in charge allotted 50 minutes of lesson time for instruction on 'extracts variates that respond to the given variate with regard to real phenomena' when the unit was introduced. Control group A did not receive this type of instruction; therefore, the compiled data for that group was separated from the rest.

We look at the response situation for stages [I] and [II] by year level. To do this, the appropriate number of responses for (1) was based on more than two. This is because at least two variates must be extracted when considering the relationship of two variates. Regarding (3), it was based on more than one.

\section{RESULTS}

First, Group A was compared with Groups B, C, D and E for Year 1. The proportion of students who gave zero responses for (1) was clearly lower for Groups B, C, D and E compared to Group A, and the proportion of students with more than two responses was particularly high. On the whole, the response situation for Groups B, C, D and E was clearly better. Regarding subquestions (i) and (ii) for (3), the proportion of students who gave no response was clearly lower for Groups B, C, D and E compared to Group A, and the proportion of students with more than one response was high. Generally, the response situation for Groups B, C, D and E was clearly better.

Next, we look at the response situation for stages [I] and [II] by year level. 
For Year 1, the number (proportion) of students who gave more than two appropriate responses for (1) was 6 and 71 for Group A and Groups B, C, D and E, respectively, with 77 students (59.2\%) in total. However, the number (proportion) of students who gave less than one response was 24 and 59 for Group A and Groups B, C, D and E, respectively, with 83 students (51.9\%) in total. The number (proportion) of students who gave more than one response for (3) was 8 and 74 for Group A and Groups B, C, D and E, respectively, with 82 students (51.3\%) in total. However, the number (proportion) of students who gave no response was 22 and 56 for Group A and Groups B, C, D and E, respectively, with 78 students (48.8\%) in total.

For Year 2, the number (proportion) of students who gave more than two appropriate responses for (1) was 77 (59.2\%). However, the number (proportion) of students who gave less than one response was 66 (43.4\%). The number (proportion) of students who gave more than one appropriate response for the response situation of (3) was 74 (48.7\%). However, the number (proportion) of students who gave no response was 78 (51.3\%).

For Year 3, the number (proportion) of students who gave more than two appropriate responses for (1) was 65 (44.2\%). However, the number (proportion) of students who gave less than one response was $82(55.8 \%)$. The number (proportion) of students who gave more than one appropriate response for the response situation of (3) was 52 (35.4\%). However, the number (proportion) of students who gave no response was 95 (64.6\%).

\section{DISCUSSION}

The objectification of the method is demonstrated in van Hiele's theory; therefore, it was thought that the students who could not attain a certain level would have difficulty in achieving levels beyond this point. Based on van Hiele's levels, Isoda (1987) proposed levels of thinking for functions: 'Level 0: The phenomenon (object) can be studied as a relationship between 2 quantities and the dependency between the phenomena. Level 1: The relationship between the quantities (object) can be studied by looking at the properties of change and relationship. Level 2: The properties of change and relationships (object) can be studied through functions and graphs. Level 3: The properties of function equations and graph changes (object) can be studied through functions (derivative, primitive functions). Level 4: The generic function (object) can be studied through function space'. Based on these levels, '[I] Extract a variate from a phenomenon, [II] Relate the 2 extracted variates', becomes the thinking method for Level 0 and at the same time becomes the object of thought for Level 1, which in turns forms the foundation for understanding functions. If stages [I] and [II] are lacking, it is expected that it would be difficult to understand the definitions of functions and function equations and graphs at a higher level. Therefore, one of the difficulty factors behind students' understanding of functions can be found in these stages.

The focus of this research was on the prototypical stages of understanding functions [I] and [II], which has not been the focus of much research. The study surveyed junior high school students. When comparing students across three years, we found that the response situation for stages [I] and [II] did not change for the better as the class progressed, although we assumed it would under ordinary circumstances. Moreover, the results showed that roughly half of the students experienced problems with stages [I] and [II] across all year levels. In fact, interviews with the students' mathematics teachers indicated that students at all the three year levels had problems with the field of functions compared with the other areas. However, when the teacher provided 50 minutes of foundational instruction, which focused on 'extracting variates that respond to the given variate with regard to real phenomena', before the unit was introduced, this proved effective to a certain degree with regard to stages [I] and [II]. Thus, it was necessary for the students who were the subjects of this study to receive tailored instruction related to stages [I] and [II]. However, the extent to which the students retained such information is unknown still; therefore, further research is needed.

It can be concluded that one of the difficulty factors behind students' understanding of functions is that their conception of stages [I] and [II] has not been adequately formed. In other words, it is possible that, even though students are not able to adequately attain this level, they are being taught content related to a higher level, which leads to difficulty in understanding functions. Therefore, the study suggests that this may be one of the difficulty factors behind the understanding of functions. However, the issues that were examined in this study may not necessarily set out problems to be solved regarding real phenomena. It is necessary to keep in mind that when there are problems students want to solve on real phenomena, one variable will be specified, so the result may not be the same. 


\section{Disclosure statement}

The author reports no potential conflict of interest.

\section{Notes on contributors}

Yoshiki Nisawa - Department of Education, Faculty of Education, Bukkyo University, Japan.

\section{ACKNOWLEDGEMENT}

This work was supported by JSPS KAKENHI Grant Number 17K04823.

The authors would like to thank Enago (www.enago.jp) for the English language review.

\section{REFERENCES}

Colignatus, T. (2014) Pierre van Hiele, David Tall and Hans Freudenthal: Getting the facts right. Retrieved on 18 April 2018 from https://arxiv.org/ftp/arxiv/papers/1408/1408.1930.pdf

Fuys, D., Geddes, D., \& Tischler, R. (1988) The van Hiele model of thinking in geometry among adolescents. Journal for Research in Mathematics Education Monograph, 3. Reston, Va.: National Council of Teachers of Mathematics, 1988. https://doi.org/10.2307/749957

Isoda, M. (1987) Level of thought regarding functions and research on its instruction. Journal of Japan Society of Mathematical Education, 69(3), 82-92.

Japan Society of Mathematical Education (ed.) (2010) Handbook of Research in Mathematics Education. Tokyo: Toyokan Syuppan.

Land, J. E. (1990) Appropriateness of the van Hiele model for describing students' cognitive processes on algebra tasks as typified by college students' learning of functions. Boston, MA: Boston University.

Ministry of Education, Culture, Sports, Science and Technology. (2008) Junior high school curriculum guidelines Commentary Mathematics. Tokyo: Education Publishing.

National Institute for Educational Policy Research. (2008, 2014, 2015, 2016, 2017). 'Curriculum Research Center "National Assessment of Academic Ability" Assessment questions, Correct answer examples, $\begin{array}{lllllll}\text { Explanatory materials'. } & \text { Retrieved } & \text { on } & 7 & \text { September } & 2017 & \text { from }\end{array}$ http://www.nier.go.jp/kaihatsu/zenkokugakuryoku.html

OECD (Organization for Economic Cooperation and Development) (2017) PISA 2015 Assessment and Analytical Framework: Science, Reading, Mathematic, Financial Literacy and Collaborative Problem Solving, revised edition. PISA, Paris: OECD Publishing.

Usiskin, Z. (1982) Van Hiele Levels and Achievement in Secondary School Geometry. Chicago: University of Chicago, 1982. ERIC Document Reproduction Service no. ED 220288.

Van Hiele, P. M. (1986) Structure and insight: A theory of mathematics education. Orland, FL: Academic Press.

Walsh, R. (2015). A purpose-built model for the effective teaching of trigonometry: a transformation of the van Hiele model (PhD thesis), University of Limerick. Retrieved on 18 April 2018 from http://hdl.handle.net/10344/4660 